\title{
SOUNDSCAPE, CULTURAL LANDSCAPE AND CONNECTIVITY
}

\author{
Kumi Kato
}

\begin{abstract}
'Soundscape' is a landscape of sound or sonic environment that focuses on the way a sound is perceived and understood by individuals and social groups. With the special and temporal qualities of sound, the concept presents a more inclusive and holistic way of knowing a place. Attention to sounds distinct to a certain place, especially those distinct to certain human-nature interactions, allows new ways of sensing a place and producing connectivity (or lack of it). Taking soundscape as a conceptual framework and incorporating notions such as cultural landscape and intangible cultural heritage, this article explores the role of sound in defining and articulating human-nature connectivity through a particular whistle noise that is symbolic to the traditional culture of ama divers in Japan. It is a phenomenological enquiry into a sustainable humannature relationship where the intangibility of this relationship is recognized and reified in a sound.
\end{abstract}

\section{INTRODUCTION}

'Soundscape' refers to an environment of sound or sonic environment that focuses on the way noises are perceived and understood at all levels of culture from the individual to the social institution. The concept of soundscape, as Paul Rodaway (1994) defines it in his book Sensuous Geographies, is not merely a state of being with respect to the sound in the environment but is also an experiential process and an auditory engagement with the environment that continually changes with our way of interaction. Being in a soundscape is a bodily experience in which one's body resonates with the environment, placing one inside the landscape, connecting humans with their environment. Soundscapes allow for a holistic conceptualization of human-nature relationship represented by a place-specific sound. 
With soundscape as a conceptual framework, this article locates a 'sound in place' that expresses human ethics towards-and connectivity with-the natural environment. It defines such soundscapes symbolically as a 'sustainable' human-nature relationship whereby sound articulates intangible qualities (i.e. human ethics, spirituality), which are further defined as intangible cultural heritage for (specifically related to) sustainability. This concept will be discussed with a reference to the author's study of a soundscape of women divers in Japan (ama), in which sound is a symbolic representation of their connectivity with the ocean environment. Conservation ethics and a sense of connectivity of those who exploit natural resources is the core of the research, to which the discussion can now be directed.

SOUNDSCAPE AS A CULTURAL SPACE OF HUMAN-NATURE CONNECTIVITY

One critical ingredient for the development of a conservation ethic is a sense of connectivity with the natural world, or in the terms of the eco-philosopher David Abram, the 'more-than-human-world' (Abram 1997: ix). Concepts such as 'to live in place' (Thayler 2003), 're-inhabiting' (Berg and Dasmann 1990) and 'insideness' (Relph 1979) also articulate such connectivity and human position in relation to the natural world. Connectivity here is genius loci (spirit of place), an authentic integrity of a place sustained over time through ordinary and on-going human-nature interactions (Hay 2002). This ordinariness of interaction is important. Plumwood (2002:220) warns that simply designating a place as special or sacred may be ineffective in countering the devaluation, degradation and instrumentalisation of ordinary land'. Spiritual connection with a place should develop out of ordinary interaction with a place and generate a better earth ethics and culture that contain a certain type of capacity for communication which can recognize those elements that are life supporting. The kind of relationship generated here is dialogical and communicative. It is both two-way and two-place, whereby people can belong to the land as much as it belongs to people (Plumwood 2002).

Such a communicative paradigm suggests that a sustainable relationship with the natural environment can only be realized though an effort to make the relationship in some way reciprocal, even symbolically and conceptually. Landscape, as a result, becomes a story that shows a deep acquaintance and dialogical interaction. Such interwoven landscapes that reflect human-nature connectivity, may be defined as a 'cultural landscape', which the International Council on Monuments and Sites (ICOMOs) defines as: 'a combined works of nature and humankind that express a long and intimate relationship between peoples and their natural environment' (Anonymous 2008:7). Here, human- 
nature relationships may be expressed in specific techniques of sustainable land use, communities' beliefs, and artistic and traditional customs that embody an exceptional spiritual relationship of people with nature.

Furthermore, connectivity with the natural world is sensory in nature. For instance, in his memoirs, Tom Sullivan (2007:108) posits that 'humankind is intimately bound to the world by combination of senses', and all senses - visual, auditory, olfactory, tactile and culinary - connect us with particular experience at a particular place. In Landscape: Politics and Perspectives, the anthropologist Barbara Bender similarly argues that 'an experiential or phenomenological approach allows us to consider how we move around, how we attach meaning to places, entwining them with memories, histories and stories, creating a sense of belonging' (Bender 1993:135).

On top of such phenomenological considerations, the material culture theorist Christopher Tilley (1994) adds another layer. He indicates the significant ways in which supernatural presences and ancestral powers are immanent in the landscapes of many non-Western societies. The past and the elders are implicated in the way certain groups of people understand and interact with certain sites, shaping the places of the life-world (Tilley 1994). Today, such ancestral landscapes are invisible for many urban dwellers, and environmental and social changes urge our attention to what could be in the process of becoming lost.

\section{CHALLENGES TODAY}

The UN Global Compact Cities program has reported that over 50 percent of the world's population will be living in cities by 2010, and that urban populations are faced with increasingly complex economic, social, and environmental problems (Teller 2003). The report states that urbanisation is exacerbating existing difficulties and creating new challenges, including poverty, personal safety, illiteracy, and drug use, as well as land, air and water pollution-all detrimentally impacting people and land far beyond the geographical limits of the city itself. It is ironic that the concentration of population does not lead to the formation of communities-cohesiveness, connection and sense of place generated by the members of the community. The process of 'belonging in place', Armstrong (2004: 239) argues, is critical today because 'belonging has become a confused concept under the homogeneity of globalisation. The aforementioned urban problems, as well as high mobility, technology use, and recent rises in security-related fear, hinder the formation of communities. Lack of community can lead to weaker connection with locality, and thus, to a loss of 
local distinctiveness.

The increasing difficulty for both community and individuals to maintain distinctiveness and place in contemporary society is a fundamental aspect of people's existence in the world: 'Places are fusions of human and natural order and are the significant centers of our immediate experiences of the world' (Relph 1979:141). As one's spiritual connection is recognized and developed, a place becomes a home, which is the foundation of 'our identity as individuals and members of a community' (Hay 1994:11).

The challenge of creating a sense of place can be even greater for culturally diverse societies like Australia. Such societies are particularly relevant in the contemporary context, given that diversity in global perspectives, approaches, and values is becoming an increasingly worldwide reality. Armstrong (2004) asserts that understanding how diverse communities make sense of their place - and their place-making processes - is critical because understanding people and place helps us rethink what is happening to our environments and our sense of belonging as a result of late capitalism. The importance of understanding place-making processes deserves particular attention because commitment to place is a critical ingredient of sustainability, where both social and cultural dimensions need to complement environmental aspects (Booth and Jacobs 2004; Heyd 2007; Rodman 2003).

\section{CREATIVE RESPONSE - LISTENING TO A PLACE AND EACH OTHER}

In response to the above consequences of globalization and to regain local distinctiveness and a sense of community, listening - attention to sound in the environment, or 'soundscape' - is useful. A soundscape, as outlined at the outset, is a landscape represented by sounds; a complex web of human-nature relationships embodied and conceptualised as a cultural landscape. Soundscapes, therefore, help humans to recognize their place in relation to the surrounding environment (Hedfors and Berg 2003; Macgowan 2007; Truax 1996). As Casey defines them, soundscapes are: 'Perceived and interpreted by human actors who attend to them as a way of making their place in and through the world [... they] are invested with significance by those whose bodies and lives resonate with them in social time and space' (Casey in Feld 2003: 226).

The significance of sound can be summarized in the four main points below. Firstly, sound is a means of connection and knowing a place. 'Being in a place' is a whole-body, as well as spiritual, experience where one is embedded in the landscape. Feld $(2003 ; 2005)$ defines such experience as sensuous episte- 
mology, where sense of place overlaps with physical senses. Knowing a place through auditory experience is termed 'acoustemology'. Listening to a place is therefore a way of attending to distinctive features of a place and making explicit connection with it; communicating with the environment in which one resides, to be sensitively in tune with the surrounding environment's state and flow. Defining ordinary places of daily interaction may be seen as a structuralsemiotic analysis of the traditions of habitus as ways to explain a sense of belonging or dwelling - gaining insights into how to understand a place that reflects one's everyday life. It is also a hermeneutic exploration of being-in-theworld, in which humble ordinary places are embodied as a profound sense of place (Casey 1996).

Secondly, sounds can be a means to forming a community. both human and land. Listening to a place is to identify sounds unique to the place where community is recognized. Sound may represent natural, cultural, and historical features of a place, and/or related knowledge, skills, and spirituality. In some cases, sound resides in memory (lost sound). Such 'soundmarks' (Schafer 1985), or significant sounds particular to a distinct place, become common references for a community, creating a sense of community linked to place. Soundmarks considered to be common to a specific region or city, will build an acoustic community (Truax 1984; Schafer 1985). Such auditory awareness about place becomes a sonic sense of place that can help define a conceptual community or a consciousness terrain (Berg and Dasmann 1990), as well as a community of care (Hay 2002). A community that recognizes a profound connection with a certain place would care about that place and its integrity. Such an authentic relationship is critical for sustainability. It can thus be said that an auditory awareness extends one's consciousness to be part of a land community (Leopold, 1968), where sacred connection is recognized in even ordinary, everyday places (Tacey 1995; Tayler 1999).

Thirdly, sound can be a carrier of ethics and spirituality. Sounds can carry traditional and historical knowledge of living in place and communicate the complexity of knowledge, ethics and connectivity to those outside of their world. Sounds also carry social memories about place and people. Bradley and McKinnon (2007) give an example of Yolngu people's songs that 'clearly establish an immutable relationship of what could be called the spirit of place to the spirit of people' (Bradley and McKinnon 2007:77). Yolngu people experience place through all their senses (i.e. sight, smell, sound, taste and touch). Travelling on the land and seeing and participating in their places increases people's knowledge and legitimizes their authority. Claims to rightful knowledge are often followed by emphasising one's extensive travels to distant places 
to hunt and gather seasonal food or to attend ceremonies. Through encounters of place, people increasingly define themselves though their experiences and the knowledge that this brings, constructing a cultural encyclopedia (Povinelli 1993). Clearly such sense of connection is largely being lost. But we may-by embedding into shared environments symbols that are culturally meaningful-transform space into place (Low 1999). Such a form of identifying with and committing to local distinctiveness, is one significant way of meaningmaking for place.

Lastly, sound can be a means to creative expression. Sounds can highlight the importance of creativity and imagination as expressed in many environmental soundworks (e.g. Bandt 1985; 2001). The ephemeral quality of sound allows one to be spontaneous and accepting of alternative ways of thinking. Hence, with sound one would imagine space and construct meanings much more freely. Attention to sound also emphasizes that creativity is not only expressed visually in our visually dominant lives. As such, sound is part of a process in which positive words that articulate our connection with place can be better created, circulated, and therefore influential. In other words, when thinking about the relationship between sound and sustainability, we need to consider more creative approaches for promoting auditory senses of beauty, appreciation and celebration of community life.

Here, it is also useful to refer to the concept of Intangible Cultural Heritage (ICH) defined, for example, in the UNESCO Convention for the Safeguarding of the Intangible Cultural Heritage (UNESCO 2003):

The practices, representations, expressions, knowledge, skills - as well as the instruments, objects, artefacts and cultural spaces associated therewith - that communities, groups and, in some cases, individuals recognize as part of their cultural heritage. This intangible cultural heritage, transmitted from generation to generation, is constantly recreated by communities and groups in response to their environment, their interaction with nature and their history, and provides them with a sense of identity (Article 2. para.1).

Sound itself can also be a component of $\mathrm{ICH}$, as well as a means of articulating ICH, particularly because of its transient and fleeting nature (see Kato 2007). ICH is interactive, dynamic and cohesive in that it harbours that crucial component of being something which gets transmitted from one generation to the next. Further, it is recreated constantly by groups and communities, in response to their interactions with the natural environment, as well as their 
historical conditions of existence. In this way it promotes a sense of identity and cultural continuity which has the potential of sustaining and developing human creativity and cultural diversity.

I elaborate on these premises below with an example of sound that contains the above qualities and which can easily be described as a form of Intangible Cultural Heritage for sustainability. The soundscape of a specific culture - a group of women divers in Japan (ama) - is presented as an example of a cultural landscape representing the divers' cultural heritage through the Isobue whistle sound.

\section{SOUNDSCAPE OF AMA}

Isobue, or sea whistle, is the sound of women divers (ama) taking breaths in between their dives. Ama (literally 'sea women') free dive (i.e. without oxygen tanks) for abalone, various shellfish and seaweed throughout the year. Today the traditional form of this practice is maintained in the coastal areas of Japan, Korea, and China. This present study was carried out in the island village of Sugashima, Toba-city, Mie prefecture, on the central east coast of Japan.

Ama are typically divided into two categories depending on the way they access the diving spot: one is kachido (shore divers), who swim into the ocean from the shore, typically diving in five to ten metres of water; the other is $f u$ nado (boat divers), who go out further in boats and dive in deeper water (up to 20 metres). Their dives are short and frequent, and the breaths they take between dives are a way of resting and preparing for the next dive.

The most prized harvest is abalone (awabi), fetching up to 8000 yen a kilo (approx. \$13O NZD). The harvest is strictly regulated. In the region, the abalone season is typically between June and August, although harvesting is officially allowed all year except the breeding season (between 15 September to 31 December). Decisions to 'open the sea' are made by each regional fishery union (ama division) according to tide and weather, as well as festivities, rituals, and local beliefs. The fishery unions will not 'open the sea' if there was a funeral in the village ten to forty days earlier, varying regionally. Sugashima has the least number of days (about 25). Diving time per day is also restricted from thirty minutes to one and a half hours. The definite schedule is only announced in the morning through the loud speaker at the fishing union.

Numerous rituals, festivities and self-imposed restrictions represent $a m a$ 's ethics towards the ocean environment and their gratitude towards the blessing 
they receive (Martinez 2004). It is also a way of wishing and ensuring safety, as without the requisite respect, the ocean would haunt them with life-threatening danger and even death. These restrictions were gradually implemented through time, particularly with the introduction of non-traditional equipment. It was interesting to note that many divers say that what is frightening is not the deep ocean, the cold, or even the sharks and hardship of the dive, but the word rankaku (uncontrolled harvest or over-harvesting). The divers repeatedly stated that they make sure 'they can come back tomorrow, next week, and next year' by intuitively respecting the limit, although this limit is also related to physical factors. This acute sense of ethics was most prominently expressed when new diving equipment-namely facemasks and wetsuits-was introduced in the early and mid $20^{\text {th }}$ century respectively.

Interestingly, both innovations received resistance from the ama unions for fear that they would lead to over-harvesting. The facemask would allow divers to 'see too well and take too many'. The wetsuits would allow longer dives as they protect divers from cold. Although both masks and wetsuits were both introduced in all regions eventually, various restrictions were developed on season, location and time. Sugashima was the last village to introduce facemasks (in 1965) and wetsuits (in 1988), and has the shortest diving season in the region. One woman said, 'Of course the wetsuits keep you warm, but you cannot feel the ocean', while another noted 'It felt rude to go into the sea with that black thing on'.

The introduction of wetsuits also coincided with rapid industrialization when many men took up city jobs, resulting in fewer boat handlers, leaving women to be shore divers rather than boat divers. Wetsuits resulted in new types of accidents, with some women noting that the wetsuit material created increased friction with rock surfaces. The insulating quality of wetsuits also allowed divers to take greater risks in cold water conditions. One woman added: 'Wetsuits exhaust you without you noticing as you have to swim, resisting buoyancy, [while] carrying three to four kilograms of weight'. Moreover, current technology has added another dread. The newer plastic waist cords (which used to be made of mulberry) are harder to cut if the divers ever get tangled.

The introduction of wetsuits has also led to an unfortunate increase in illegal fishing, by both recreational and commercial divers. This, together with increased use of technology (GPS, transport, storage) and mass harvesting, as well as pollution, are believed to be the main causes of the severe decline in abalone numbers (Kato 2007a). The fishery union reports that the harvest has declined to almost one tenth of what it was twenty years ago. The women also 
noticed a gradual but clear change in ocean quality: 'The seaweeds are dying like plants-in summer heat'; 'Unusual fish and shells started to appear', and 'More rubbish started to get tangled in seaweeds, sea floors and shores'.

\section{CONCLUSION}

The self-regulations, rituals, ceremonies and festivities have not only allowed a sustainable use of natural resources but also the divers' strong connections with the ocean environment. It is ironic that a number of external forces that breach such ethics have caused a decline in these resources and the practice of ama diving itself. On the morning of the divers' festival held according to the lunar calendar, a stream of city workers and high school students hurry towards the ferry terminal to go across to the city on the mainland. The stream going in the opposite direction to the festival site, are the ama (fishers, elders and young children). The life of the divers and fishers revolve around the tides (i.e. the lunar calendar), while the rest of the world follows the solar calendar introduced in 1872 . The whistle, as a sound in place, represents diverse meanings: the divers' spirituality, their connection to the ocean environment, their sense of ethics, their community, histories, stories, their joy, sadness and hardship. The ama soundscape can be seen as a cultural landscape within which a sustainable human-nature relationship, mythology, rituals, festivities, community life and personal stories, are imbedded.

In the soundscape of $a m a$, the whistle blending with the sound of the ocean carries the spirits of the divers, their stories and timeless connection with the world they lived in. Despite the reality of social and environmental changes, the sound symbolizes the essence of humanity situated in their place as the fundamental wisdom for sustainability. By creatively defining a place and listening to the surroundings (and to each other), an invisible, yet tangible, sense of place emerges. Attention to sound and soundscape therefore offers a more holistic approach to sustainability that embraces social, cultural, and environmental dimensions. There, resonance of the acoustic materiality of a place is embodied in human-nature interactions.

\section{REFERENCES}

Abram, David 1997 The Spell of the Sensuous: Perception and Language in a MoreThan-Human World. New York: Vintage Books.

Anonymous 2008 World Heritage Cultural Landscapes. Paris: ICOMOs. 
Armstrong, Helen 2004 'Making the unfamiliar familiar: research journeys towards understanding migration and place', Landscape Research. 29(3):23760.

Bandt, Ros 2001 Sound Sculpture: Intersections in Sound and Sculpture in Australian Artworks. Sydney: Craftsman House.

1985. Sound in Space: Wind Chimes and Sound Sculptures. Camberwell: Victorian Arts Council and Council of Adult Education.

Bender, Barbara (ed) 1993 Landscape: Politics and Perspectives. Oxford: Berg.

Berg, Peter and Dasmann, Raymond 1990 'Reinhabiting California', in V. Andruss, C. Plant, J. Plant and E. Wright (eds) Home! A Bioregional Reader. Philadelphia: New Society:

Booth, Annie and Jacobs, Harvey L. 2004 'Ties that bind: Native American beliefs', in B. Foltz, and R. Frodeman (eds) Rethinking Nature: Essays in Environmental Philosophy. Bloomington: Indiana University Press:

Bradley, John and McKinlay, Elizabeth 2007 'Singing the land, singing the family: Song, place and spirituality amongst the Yanyuwa', in F. Richards (ed) The Soundscapes of Australia: Music, Place and Spirituality. Aldershot: Ashgate: 75-92.

Casey, Edward 1996 'How to get from space to placer in a fairly short stretch of time: Phenomenological prolegomena', in S. Feld and K. Basso (eds) Senses of Place. Santa Fe, New Mexico: School of American Research Press: 13-52.

Feld, Steven 2003 'Rainforest acoustemology', in M. Bull and L. Back (eds) The Auditory Culture Reader. New York: Berg: 223-39.

2005 'Places sensed, senses placed: Towards a sensuous epistemology of environments' in D. Howes (ed), Empire of the Senses: The Sensual Culture Reader. New York: Berg: 179-91.

Hay, Peter 2002 Main Currents in Western Environmental Thought. Sydney: University of Nsw Press.

1994 'Introduction' in J. De Gryse, and A. Sant (eds), Our Common Ground: A Celebration of Art, Place and Environment. Hobart: The Centre for En- 
vironmental Studies, University of Tasmania. The Australian Institute of Landscape Architects:11-15.

Hedfors, Per and Berg, Per G. 2003 'The sounds of two landscape settings: auditory concepts for physical planning and design', Landscape Research. 28(3): 245-63.

Heyd, Thomas 2007 Encountering Nature: Towards an Environmental Culture. Aldershot: Ashgate.

Kato, Kumi 2007 'Prayers for the whales: spirituality and ethics of a former whaling community', International Journal of Cultural Property. 14(3):283-313.

— 2007a 'Waiting for the tide, tuning in the world - ama no isobue: soundscape of abalone diving women', in R. Bandt, M. Duffy and D. MacKinnon (eds) Hearing Places. Sound, Place, Time, Culture. Newcastle: Cambridge Scholars Press: 214-233.

Leopold, Aldo 1968 A Sand County Almanac, and Sketches Here and There. Oxford: Oxford University Press.

Low, Nicholas (ed) 1999 Global Ethics and Environment. London: Routledge.

Martinez, Dolores 2004 Identity and Ritual in a Japanese Diving Village. Honolulu: University of Hawaii Press.

Megowan, Fiona 2007 Melodies of Mourning: Music \& Emotion in Northern Australia. Oxford: James Currey Publishers.

Plumwood, Val 2002 Environmental Culture: The Ecological Crisis of Reason. London: Routledge.

Povinelli, Elizabeth 1993 Labor's Lot: The Power, History, and Culture of Aboriginal Action. Chicago: University of Chicago Press.

Relph, Edward 1979 Place and Placelessness. London: Pion.

Rodaway, Paul 1994 Sensuous Geographies: Body, Sense \& Place. London: Routledge.

Rodman, M. 2003 'Empowering place: Multilocality and multivocality', in S. Low 
and L. Laurence-Zuniga (eds), The Anthropology of Space and Place: Locating Culture. Malden, MA: Blackwell: 205-23.

Schafer, R. Murray. 1985 'Acoustic space', in D. Seamon and R. Mugerauer (eds), Dwelling, Place and Environment. Dordrecht: Martinus Nijhoff Publishers: $87-98$.

Sullivan, Tom 2007 Adventure in Darkness: Memoirs of an Eleven-Year-Old Blind Boy. Nashville, TN: Thomas Nelson.

Tacey, David. J. 1995 Edge of the Sacred: Transformation in Australia. Sydney: Harper Collins.

Tayler, Ken 1999 'Exploring the ordinarily sacred', Landscape Australia. 2:107-12.

Teller, David. 2003 'Global Compact Cities Program: Melbourne Model - solving hard urban issues together', Journal of Corporate Citizenship. Available at: http://goliath.ecnext.com/coms2/gi_o199-3103702/United-Nations-GlobalCompact-cities.html.

Thayler, Ray 2003 LifePlace: Bioregional Thought and Practice. Berkeley: University of California Press.

Tilley, Christopher 1994 A Phenomenology of Landscape: Places, Paths, and Monuments. Oxford: Berg.

Truax, Barry 1996 Soundscape, Acoustic Communication and Environmental Sound Composition. Norwood, NJ: Ablex.

1984 Acoustic Communication. Norwood, NJ: Ablex.

UNEsco 2003 'Convention for Safeguarding of the Intangible Cultural Heritage: Article 2', Available at: http://www.unesco.org/culture/ich/index.php?lg=EN (accessed on 5 Oct, 07). 